Check for updates

Cite this: RSC Adv., 2021, 11, 22661

\section{Synthesis and characterization of $\mathrm{AFe}_{2} \mathrm{O}_{4}(\mathrm{~A}: \mathrm{Ni}, \mathrm{Co}$, $\mathrm{Mg}$ )-silica nanocomposites and their application for the removal of dibenzothiophene (DBT) by an adsorption process: kinetics, isotherms and experimental design}

\author{
Fahimeh Vafaee, ${ }^{a}$ Samira Mandizadeh, ${ }^{\mathrm{b}}$ Omid Amiri, ${ }^{\text {cd }}$ Mansour Jahangiri ${ }^{* a}$ \\ and Masoud Salavati-Niasari (D)*b
}

The kinetics, equilibrium, and statistical aspects of the sulfur removal process from hydrocarbon fuels by $\mathrm{AFe}_{2} \mathrm{O}_{4}$-silica nanocomposites ( $\mathrm{A}$ : $\mathrm{Ni}, \mathrm{Mg}$, and $\mathrm{Co}$ ) have been investigated in the present study. Nanocomposites were prepared via the auto-combustion sol-gel method and then employed in the adsorptive desulfurization (ADS) process. Next, the prepared samples were characterized by different analytical methods including XRD, SEM, TEM, FT-IR, TGA, and BET. The contributions of conventional parameters including adsorbent dosage and contact time were then studied by central composite design (CCD) under response surface methodology (RSM). Based on the statistical investigations, optimum conditions for ADS were an adsorbent dosage of $7.82 \mathrm{~g}$ per $50 \mathrm{ml}$ of the model fuel and a contact time of $32 \mathrm{~min}$. The adsorption amounts reached $38.6 \mathrm{mg} \mathrm{g}^{-1}$ for DBT. The quadratic model was applied for the analysis of variance. Based on the experimental data, the pseudo-first-order (PFO) model could explain the adsorption kinetics of the compounds. Furthermore, the Langmuir isotherm demonstrated considerable agreement with the experimental equilibrium data. According to the results, the $\mathrm{NiFe}_{2} \mathrm{O}_{4}-$ $\mathrm{SiO}_{2}$ nanocomposite showed the best performance compared to other compounds. The sulfur removal efficiency increased from 63 to $94 \%$ upon increasing the $\mathrm{NiFe}_{2} \mathrm{O}_{4}-\mathrm{SiO}_{2}$ dosage from 3 to $9 \mathrm{~g}$ per $50 \mathrm{ml}$ of the model fuel.
Received 9th April 2021 Accepted 6th June 2021 DOI: $10.1039 / \mathrm{d} 1 \mathrm{ra0} 2780 \mathrm{~h}$

rsc.li/rsc-advances ineffective for removing refractory sulfur containing compounds such as thiophene (T), benzothiophene (BT), dibenzothiophene (DBT), and 4,6-dimethyldibenzothiophene. ${ }^{6-8}$

Furthermore, harsh reaction conditions such as high pressure and temperature are required to obtain low sulfur concentrations in HDS, implying that HDS needs high operating costs for complying with low sulfur hydrocarbon fuels. ${ }^{1,3,9-14}$

It should be noted that (ADS) is a favorable method for reaching ultralow sulfur levels since it has various advantages such as low operation temperature and pressure and high selectivity. ${ }^{15,16}$

Nevertheless, the essential challenge of this method is the selection of the sorbent with high sulfur removal capacities and thio-selectivity over organosulfur compounds. ${ }^{18}$ Moreover, metal oxides have emerged as one of the possible alternative sorbents for ADS. ${ }^{19}$ A significant type of metal oxide composites, with general structural formula $\mathrm{M}^{2+} \mathrm{Fe}_{2}{ }^{3+} \mathrm{O}_{4}$ (where $\mathrm{M}=\mathrm{Mg}^{2+}$, $\mathrm{Co}^{2+}, \mathrm{Ni}^{2+}, \mathrm{Zn}^{2+}, \mathrm{Fe}^{2+}, \mathrm{Mn}^{2+}$, etc.), are spinel ferrite (SF) magnetic compounds. Extraordinary physicochemical characteristics including outstanding magnetic properties, surface active sites, high chemical stability, tunable shape and size, simplicity of 

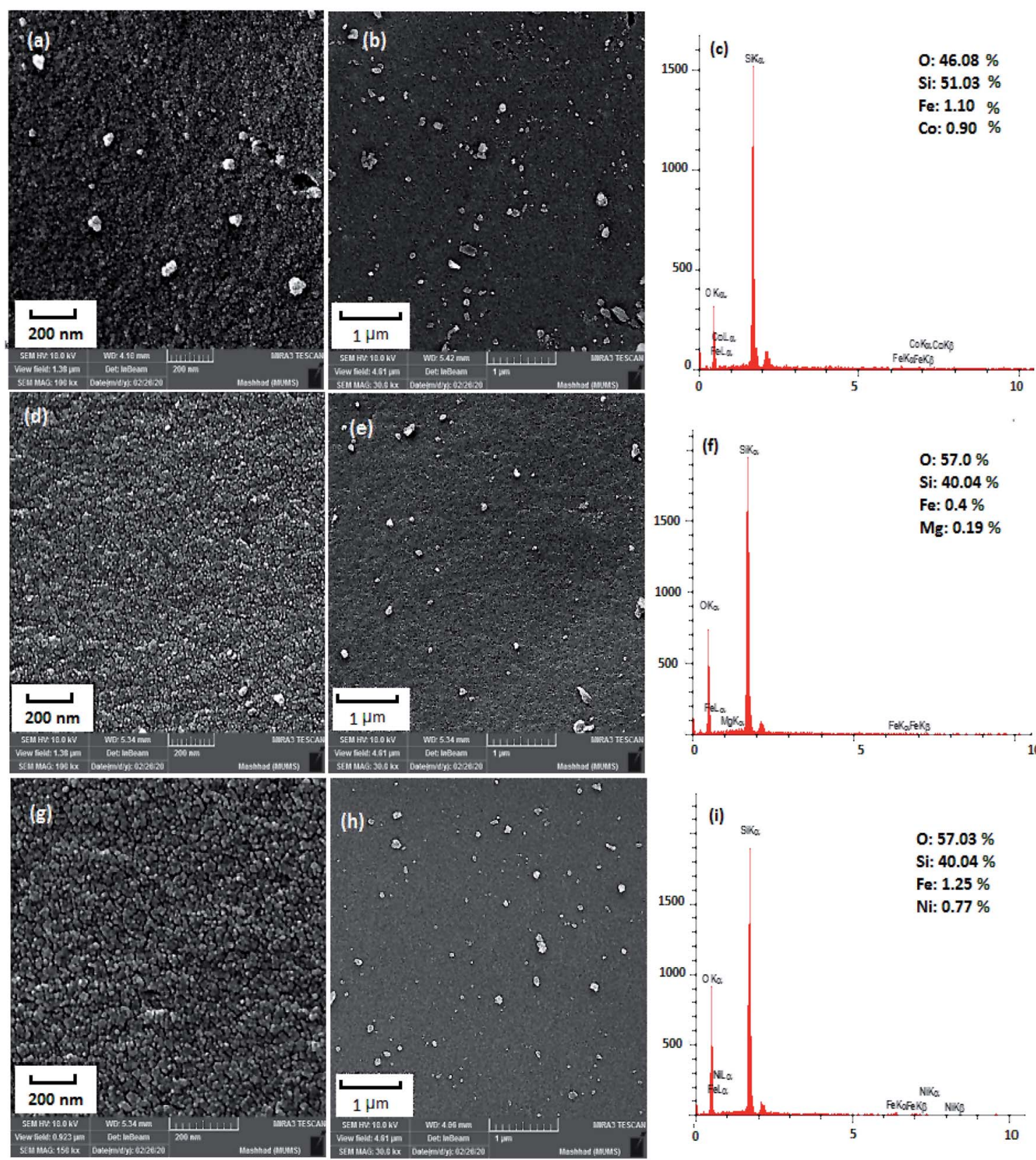

Fig. 1 SEM images and EDS spectrum of (a)-(c) sample 1, (d) -(f) sample 2, (g)-(i) sample 3.

removal after the cleaning process using an external magnetic field and the facility of modification or functionalization are the advantages of spinel ferrites. ${ }^{20,21}$ Although metal oxides are highly capable of sulfur removal, they have such drawbacks as low porosity, low surface area and volatility. ${ }^{22}$ Therefore, in order to improve the dispersion, modify the porosity, size of the pores, impart structural strength and stability, these metal oxides are loaded on the surface of different supports such as silica gel, ${ }^{23}$ activated carbon, ${ }^{10,17} \mathrm{Al}_{2} \mathrm{O}_{3},{ }^{24}$ zeolite, metal-organic frameworks and adsorbent membranes. ${ }^{25}$ The favorable

Table 1 The result of morphological for samples 1-3

\begin{tabular}{lllll}
\hline Sample & Nanocomposite & Morphology & Average particle size $^{a}(\mathrm{~nm})$ & Crystallite size $^{b}(\mathrm{~nm})$ \\
\hline 1 & $\mathrm{CoFe}_{2} \mathrm{O}_{4}-\mathrm{SiO}_{2}$ & Agglomerate & $74-175$ & 30 \\
2 & $\mathrm{MgFe}_{2} \mathrm{O}_{4}-\mathrm{SiO}_{2}$ & Semi-spherical & $76-159$ & 35 \\
3 & $\mathrm{NiFe}_{2} \mathrm{O}_{4}-\mathrm{SiO}_{2}$ & Agglomerate & $71-143$ & 48
\end{tabular}

${ }^{a}$ Obtains from Fig. 1. ${ }^{b}$ Calculates from Scherrer equation. 
properties of silica gel such as environmental friendliness, high chemical stability, low cost, variety of possible structures, range of functionalization methods and control of reactions due to lower reactivity have led to its widespread use in the industry. ${ }^{26,27}$ Similarly, Mandizade et al. evaluated the adsorption of sulfur from model fuel using $\mathrm{AFe}_{2} \mathrm{O}_{4}$ (A: Ni, $\mathrm{Cu}, \mathrm{Zn}$ )activated carbon nanocomposite and found that $\mathrm{NiFe}_{2} \mathrm{O}_{4}-$ activated carbon with BET surface area $626 \mathrm{~m}^{2} \mathrm{~g}^{-1}$ is the best
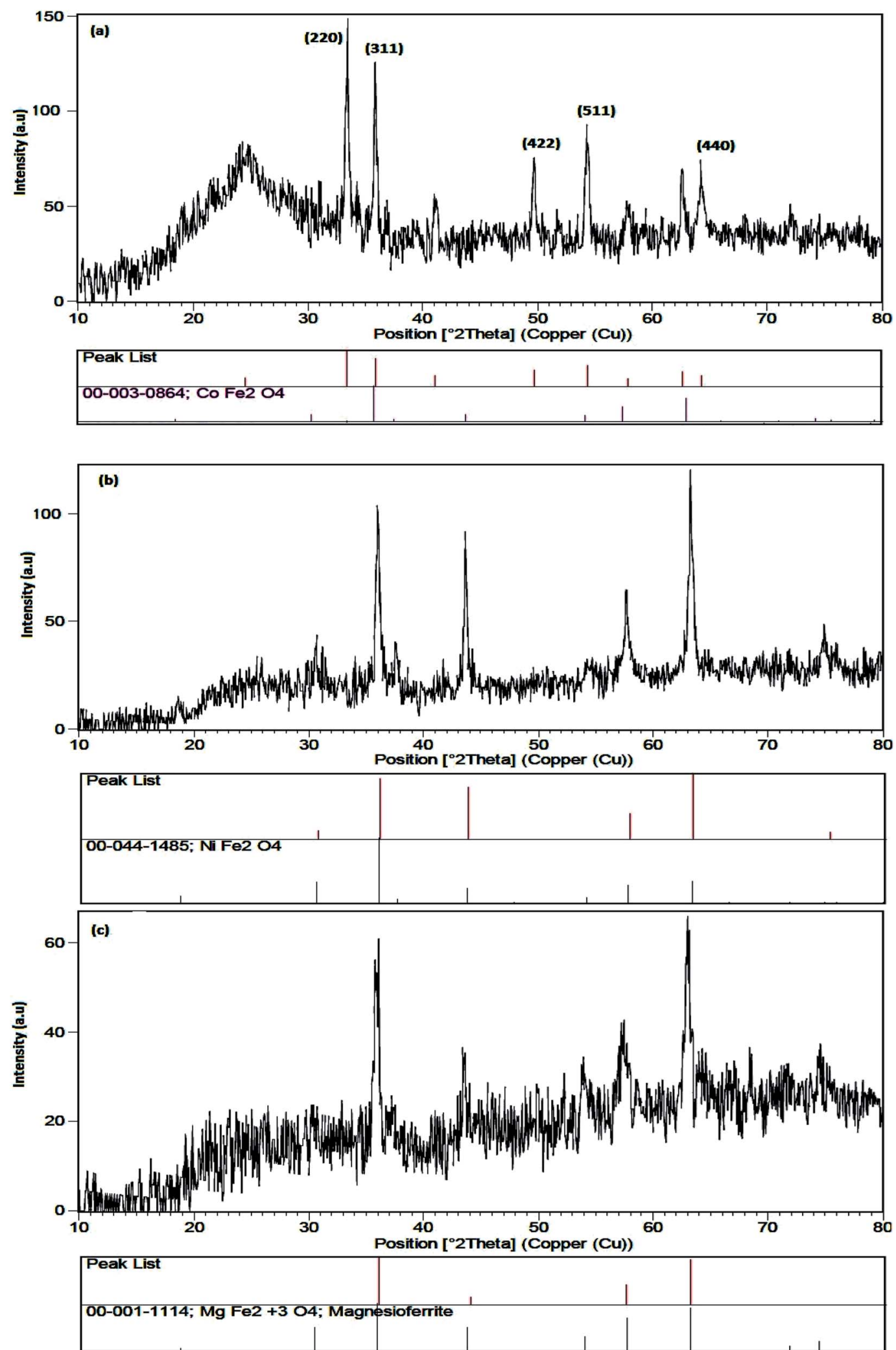

Fig. 2 XRD pattern of (a) sample 1, (b) sample 2 and (c) sample 3. 
adsorbent for producing clean fuel. ${ }^{28}$ Maximum adsorption capacity $\left(q_{\mathrm{m}}\right)$ of the $\mathrm{NiFe}_{2} \mathrm{O}_{4}-\mathrm{AC}$ nanocomposite was $108 \mathrm{mg} \mathrm{g}^{-1}$ for sulfur compound. The sulfur removal efficiency increased from 10 to $63 \%$ when the concentration of $\mathrm{NiFe}_{2} \mathrm{O}_{4}-\mathrm{AC}$ increased from 10 to $20 \mathrm{~g} \mathrm{l}^{-1}$. In this study, ferrite-silica nanocomposites have been prepared for the ADS process and the effects of the adsorbent dosage and contact time on the removal of DBT from model fuel using (CCD) as the multi-variable of the (RSD) were investigated. In this respect, the design of experiment is a technique for providing the optimization and modeling of the adsorption process. In addition, a combination of the PFO and intraparticle diffusion models was used to examine the kinetics of the adsorption process in this study.

\subsection{Preparation of nanoferrite}

Nanocrystalline ferrites $\left(\mathrm{AFe}_{2} \mathrm{O}_{4}(\mathrm{~A}=\mathrm{Ni}, \mathrm{Mg}\right.$ and $\left.\mathrm{Co})\right)$ were prepared by mixing metallic nitrates (metallic $\mathrm{A}$ and $\mathrm{Fe}$ ) and carbohydrate (sucrose). Stoichiometric amounts of metallic nitrate $\left(\mathrm{A}\left(\mathrm{NO}_{3}\right)_{2} \cdot n \mathrm{H}_{2} \mathrm{O}\right)$, ferric nitrate $\left(\mathrm{Fe}\left(\mathrm{NO}_{3}\right)_{3} \cdot 9 \mathrm{H}_{2} \mathrm{O}\right)$, and sucrose were dissolved in distilled water. The molar ratios in the mixture were 1.9 (sucrose) : 1 (metal nitrate) : 17.65 (water). Then, certain amounts of silica and ferrite $(70: 30)$ were added to the reaction vessel, which was then kept in an agate mill at $300 \mathrm{rpm}$ for $2 \mathrm{~h}$. Finally, the product was calcined at $700{ }^{\circ} \mathrm{C}$.

\subsection{Preparation of sample for adsorption process}

In this work, nanocomposites were used as novel adsorbents. The model oil was prepared by dissolving dibenzothiophene (DBT) in the $n$-hexane to obtain a sulfur content of $200 \mathrm{ppm}$. Total sulfur content was measured using a petro test calorimetric bomb C5000, according to ASTM D-1266.

\subsection{Batch mode experiments}

The adsorption studies of DBT on $\mathrm{AFe}_{2} \mathrm{O}_{4}$-silica (A: Ni, $\mathrm{Mg}$, and $\mathrm{Co})$ were conducted in a batch reactor at $60{ }^{\circ} \mathrm{C}$ and $400 \mathrm{rpm}$ under atmospheric pressure to investigate the effects of the
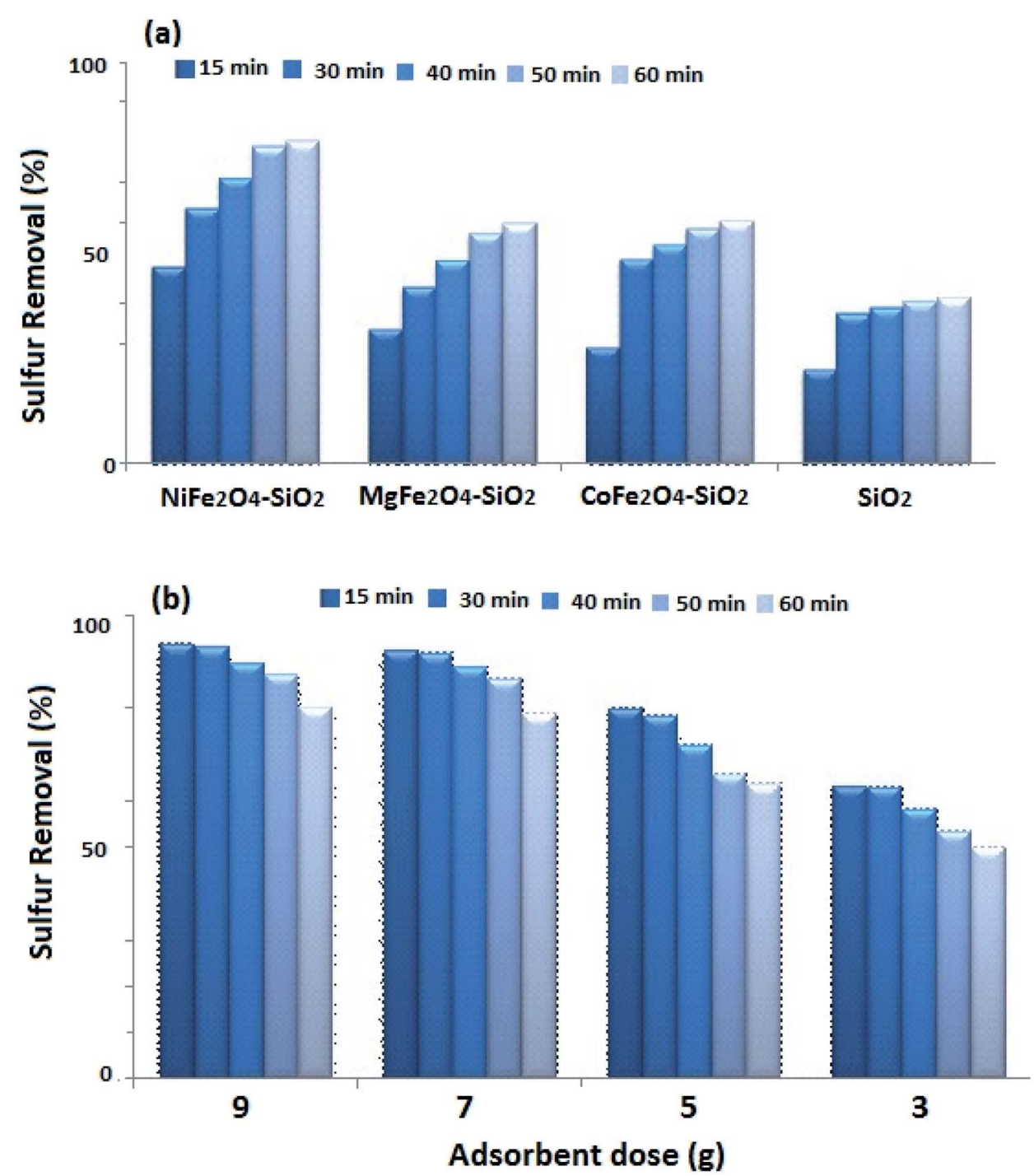

Fig. 3 (a) Effect of different adsorbents on the removal DBT from model fuel (b) effect of adsorbent dosage and constant time on adsorption of DBT on $\mathrm{NiFe}_{2} \mathrm{O}_{4}-\mathrm{SiO}_{2}$ at initial concentration 200 ppm. 


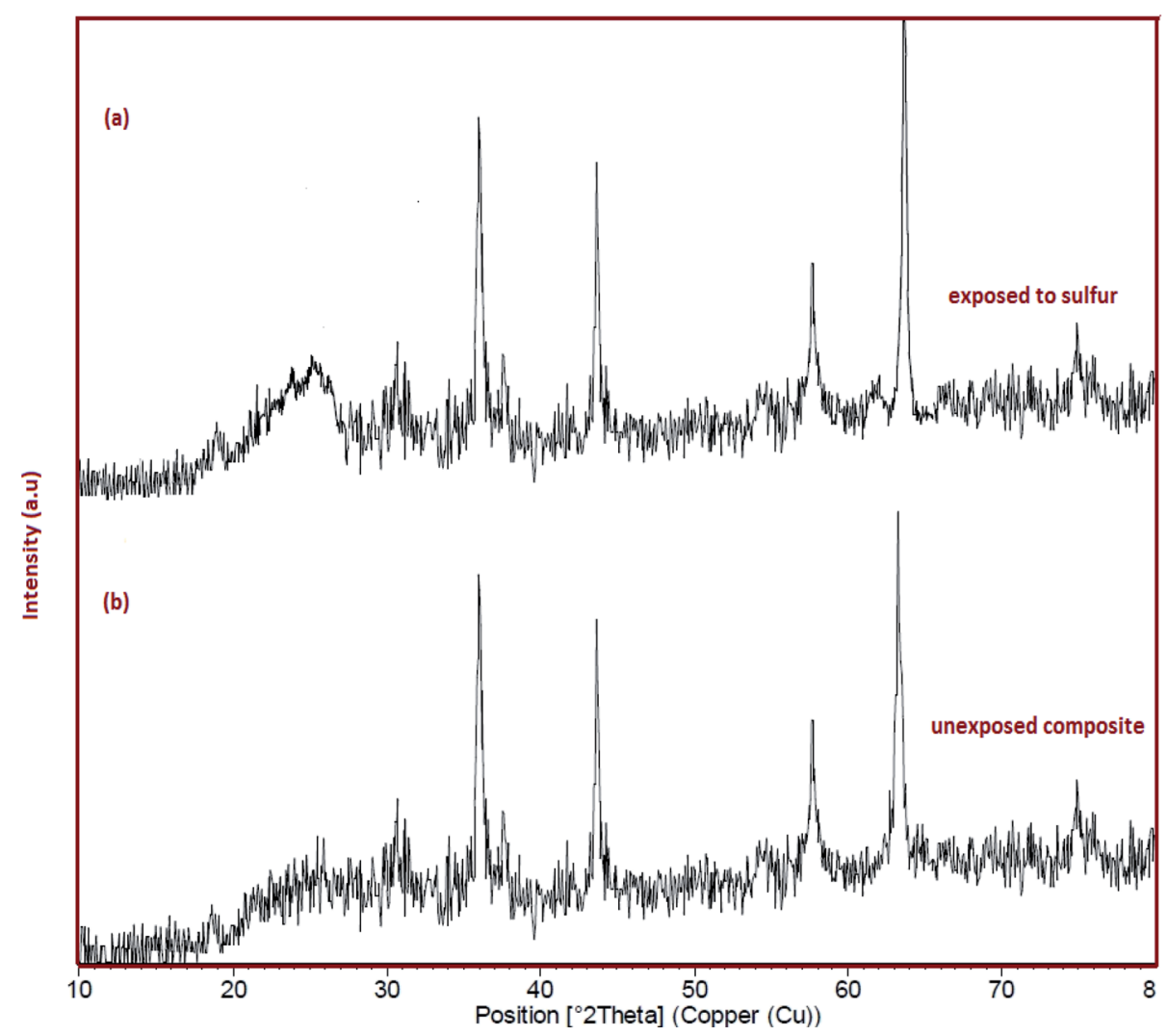

Fig. 4 (a) The XRD pattern of sample 3 after adsorption of DBT. (b) The XRD pattern of sample 3 before adsorption of DBT.

adsorbent dosage and contact time on the percentage of sulfur removal. Various dosages of the adsorbents $(1,3,5,7 \mathrm{~g})$ and time intervals of $15 \mathrm{~min}$ were used. A certain dosage of the adsorbent was added to $50 \mathrm{ml}$ of the model fuel in a conical flask. Sulfur concentration were measured using petro test XRay fluorescence sulfur meter (Tanaka scientific Ry-360sH), according to ASTM D-42946. The sorption capacity $q\left(\mathrm{mg} \mathrm{g}^{-1}\right)$ and percentage of the DBT from the solution were calculated using the following equations: ${ }^{29}$

$$
\text { Removal } \%=\frac{C_{0}-C_{\mathrm{e}}}{C_{0}} \times 100 \%, q_{\mathrm{e}}=\frac{\left(C_{0}-C_{\mathrm{e}}\right) \times V}{m}
$$

where $C_{0}$ and $C_{\mathrm{e}}$ are the initial and final concentrations $\left(\mathrm{mg} \mathrm{l}^{-1}\right)$ of DBT in the solution, respectively, $V(\mathrm{l})$ is the volume of DBT solution, and $m(\mathrm{~g})$ is the weight of sorbent.

\section{Results and discussion}

The microstructures of the as-prepared products were characterized by SEM. SEM images and EDX spectrum of the $\mathrm{CoFe}_{2} \mathrm{O}_{4}-$ $\mathrm{SiO}_{2}, \quad \mathrm{MgFe}_{2} \mathrm{O}_{4}-\mathrm{SiO}_{2}, \quad \mathrm{NiFe}_{2} \mathrm{O}_{4}-\mathrm{SiO}_{2}$ nanocomposites were shown in Fig. 1a-c, Fig. 1d-f, Fig. 1g-i, respectively. SEM observations illustrate the presence of spherical nanoferrites homogeneously dispersed over the silica matrix. It is clearly

Table 2 Comparison of textural properties and S adsorption capacity of different adsorbents

\begin{tabular}{|c|c|c|c|c|c|}
\hline Adsorbents' & $\begin{array}{l}\text { Specific surface } \\
\text { area }\left(\mathrm{m}^{2} \mathrm{~g}^{-1}\right)\end{array}$ & $\begin{array}{l}\text { Total pore } \\
\text { volume }\left(\mathrm{cm}^{3} \mathrm{~g}^{-1}\right)\end{array}$ & Pore size $(\mathrm{nm})$ & $\begin{array}{l}\text { Sulfur adsorption } \\
\left(\mathrm{mmol}_{\mathrm{S}} \mathrm{g}_{\mathrm{Ads}}{ }^{-1}\right)\end{array}$ & Model fuel \\
\hline AC-Ni $\mathrm{Fe}_{2} \mathrm{O}_{4}$ (ref. 28) & 626 & 0.082 & 6.20 & 0.048 & (Dodecanethiol)RSH in $n$-octane \\
\hline W-type $\mathrm{BaFe}_{18} \mathrm{O}_{27}$ (ref. 54) & - & - & - & 0.011 & Thiophene in $n$-heptane \\
\hline $\mathrm{Ni} / \mathrm{SiO}_{2}-\mathrm{Al}_{2} \mathrm{O}_{3}$ (ref. 53) & 157 & 0.052 & 5.30 & 0.037 & $\mathrm{DBT}+4,6-\mathrm{DMDBT}$ \\
\hline $\mathrm{AC}^{1}$ & 215 & 0.074 & 10.40 & 0.017 & $\begin{array}{l}\mathrm{T}+\mathrm{BT}+\mathrm{DBT}+4,6-\mathrm{DMDBT}+5 \text {-methyl-1- } \\
\mathrm{BT}\end{array}$ \\
\hline $\mathrm{CuCo} / \mathrm{AC}^{1}$ & 174 & 0.076 & 10.80 & 0.019 & \\
\hline Silica gel ${ }^{55}$ & 349 & 0.95 & 8.00 & 0.001 & $\begin{array}{l}\mathrm{T}+2-\mathrm{MT}+3-\mathrm{MBT}+4,6-\mathrm{DMDBT} \text { in } n- \\
\text { dodecane }\end{array}$ \\
\hline $\mathrm{NiFe}_{2} \mathrm{O}_{4}-\mathrm{SiO}_{2}$ (present work) & 501 & 0.272 & 2.17 & 0.002 & DBT in $n$-hexane \\
\hline $\mathrm{MgFe}_{2} \mathrm{O}_{4}-\mathrm{SiO}_{2}$ (present work) & - & - & - & 0.013 & DBT in $n$-hexane \\
\hline $\mathrm{CoFe}_{2} \mathrm{O}_{4}-\mathrm{SiO}_{2}$ (present work) & - & - & - & 0.013 & DBT in $n$-hexane \\
\hline $\mathrm{SiO}_{2}$ (present work) & - & - & - & 0.009 & DBT in $n$-hexane \\
\hline
\end{tabular}


observed that silica is in a network texture with pores and ferrites with semi-spherical morphology are within the silica gel. It can also be concluded that some small aggregates of ferrite, which appear darker, are supported on the brighter surface of the silica. The agglomerates are structures consisting of many smaller ferrite units with a size in the range of 50-100 $\mathrm{nm}$. The results of morphological observations are summarized in Table 1. According to the EDX spectrum the presence of metal, $\mathrm{Fe}, \mathrm{O}$ and $\mathrm{Si}$ can confirm the high purity of the products.

Fig. 2 shows the XRD patterns of representative samples of ferrites. Phase type, crystal structure, product purity and the size of crystalline grains were measured by XRD pattern. Fig. 2a-c show the XRD images of $\mathrm{CoFe}_{2} \mathrm{O}_{4}-\mathrm{SiO}_{2}, \mathrm{MgFe}_{2} \mathrm{O}_{4}-\mathrm{SiO}_{2}$ and $\mathrm{NiFe}_{2} \mathrm{O}_{4}-\mathrm{SiO}_{2}$, respectively. In Fig. 2a, the diffraction peaks in $2 \theta=32.89^{\circ}, 34.60^{\circ}$, $49.21^{\circ}$, and $58.95^{\circ}$ are related to the $\mathrm{CoFe}_{2} \mathrm{O}_{4}$ with the standard diffraction pattern (JCPDS Card No. 03-0864). In the XRD patterns of the $\mathrm{MgFe}_{2} \mathrm{O}_{4}-\mathrm{SiO}_{2}$ and $\mathrm{NiFe}_{2} \mathrm{O}_{4}-\mathrm{SiO}_{2}$ (Fig. 2b and c), the broad peaks correspond to a nanosized spinel phase $\left(\mathrm{MgFe}_{2} \mathrm{O}_{4}, \mathrm{NiFe}_{2} \mathrm{O}_{4}\right)$ superimposed on the amorphous silica halo. As shown in Fig. 2, for all samples, no impurity peaks were observed, indicating the high purity of the products were observed. The sharp peaks in the diffraction pattern are due to the high crystallization of the obtained products using the Scherrer equation, the crystal size of $\mathrm{CoFe}_{2} \mathrm{O}_{4}$, $\mathrm{MgFe}_{2} \mathrm{O}_{4}$ and $\mathrm{NiFe}_{2} \mathrm{O}_{4}$ were 30, 35, $48 \mathrm{~nm}$ for samples 1, 2 and 3, respectively.
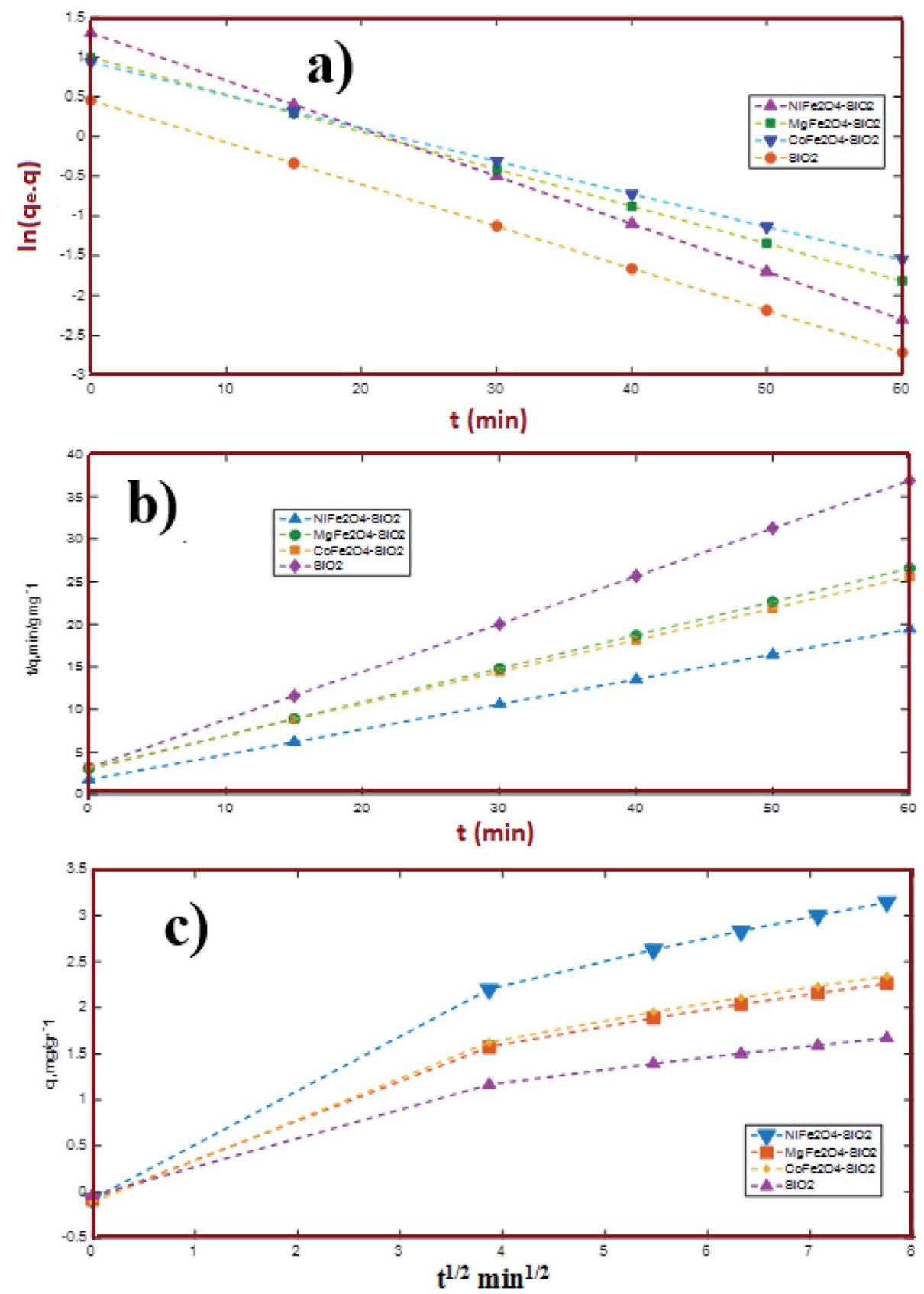

Fig. 5 Result of kinetic analysis, (a) pseudo-first order model, (b) pseudo-second order model and (c) intraparticle diffusion model. 
Adsorption amounts are changed by concentration and nanocomposite type. Fig. 3a displays the comparison of $\mathrm{AFe}_{2} \mathrm{O}_{4}$ $(\mathrm{A}=\mathrm{Ni}, \mathrm{Mg}$, and $\mathrm{Co})-\mathrm{SiO}_{2}$ nanocomposite performance in the desulfurization process. As shown, silica gel loaded with nanoferrite has higher sulfur adsorption efficiency compared to the $\mathrm{SiO}_{2}$. As depicted in Fig. 4a, $\mathrm{NiFe}_{2} \mathrm{O}_{4}-\mathrm{SiO}_{2}$ shows the best performance among all adsorbents. This could be due to the spinel structure of $\mathrm{NiFe}_{2} \mathrm{O}_{4}$, which is not destroyed in the atmosphere. ${ }^{30,31}$ According to Fig. 4, the chemical environment of the majority of metals atoms in the spinel structure are unchanged upon adsorption of sulfur compounds. This indicates that the adsorption of sulfur compounds has no effect on the MNP crystal structure of $\mathrm{NiFe}_{2} \mathrm{O}_{4}$. In addition, doped $\mathrm{Ni}$ can be applied to improve direct sulfur-adsorbent interaction. ${ }^{20}$ In this study, the effect of the adsorbent dosage on the ADS was investigated by varying the adsorbent concentration from 3 to $9 \mathrm{~g}$ per $50 \mathrm{ml}$ of the model fuel. As illustrated in Fig. $3 \mathrm{~b}$, the sulfur removal efficiency increases from 63 to $94 \%$ when the dosage of $\mathrm{NiFe}_{2} \mathrm{O}_{4}-\mathrm{SiO}_{2}$ increases from 3 to $9 \mathrm{~g}$ per $50 \mathrm{ml}$ of the

Table 3 Extrapolation results and coefficients of the pseudo-first and pseudo-second order adsorption kinetic models and intraparticle diffusion model $(1 \mathrm{~g}$ of adsorbent; $50 \mathrm{ml}$ model fuel with an initial concentration of $200 \mathrm{mg} \mathrm{DBT}, T=60^{\circ} \mathrm{C}$ )

Extrapolation result

\begin{tabular}{lll}
\hline Adsorbent & $q_{\mathrm{e}, \text { ext }}\left(\mathrm{mg} \mathrm{g}^{-1}\right)$ & $R^{2}$ \\
\hline $\mathrm{NiFe}_{2} \mathrm{O}_{4}-\mathrm{SiO}_{2}$ & 3.30 & 0.9900 \\
$\mathrm{MgFe}_{2} \mathrm{O}_{4}-\mathrm{SiO}_{2}$ & 2.54 & 0.9945 \\
$\mathrm{COFe}_{2} \mathrm{O}_{4}-\mathrm{SiO}_{2}$ & 2.65 & 0.9945 \\
$\mathrm{SiO}_{2}$ & 1.73 & 0.9945
\end{tabular}

Order pseudo-first

\begin{tabular}{|c|c|c|c|}
\hline order & Model & & \\
\hline Adsorbent & $K_{1}\left(\min ^{-1}\right)$ & $q_{\mathrm{e}, \mathrm{cal}}\left(\mathrm{mg} \mathrm{g}^{-1}\right)$ & $R^{2}$ \\
\hline $\mathrm{NiFe}_{2} \mathrm{O}_{4}-\mathrm{SiO}_{2}$ & 0.0611 & 3.68 & 0.97 \\
\hline $\mathrm{MgFe}_{2} \mathrm{O}_{4}-\mathrm{SiO}_{2}$ & 0.0468 & 2.70 & 0.98 \\
\hline $\mathrm{COFe}_{2} \mathrm{O}_{4}-\mathrm{SiO}_{2}$ & 0.0413 & 2.54 & 0.98 \\
\hline $\mathrm{SiO}_{2}$ & 0.0289 & 1.57 & 0.97 \\
\hline Pseudo-second-order & Model & & \\
\hline Adsorbent & $K_{1}\left(\min ^{-1}\right)$ & $q_{\mathrm{e}, \mathrm{cal}}\left(\mathrm{mg} \mathrm{g}^{-1}\right)$ & $R^{2}$ \\
\hline $\mathrm{NiFe}_{2} \mathrm{O}_{4}-\mathrm{SiO}_{2}$ & 0.048 & 3.40 & 0.96 \\
\hline $\mathrm{MgFe}_{2} \mathrm{O}_{4}-\mathrm{SiO}_{2}$ & 0.051 & 2.54 & 0.9 \\
\hline $\mathrm{COFe}_{2} \mathrm{O}_{4}-\mathrm{SiO}_{2}$ & 0.040 & 2.67 & 0.9 \\
\hline $\mathrm{SiO}_{2}$ & 0.099 & 1.78 & 0.9 \\
\hline
\end{tabular}

Intraparticle

\begin{tabular}{lllll}
\cline { 1 - 1 } diffusion & & Model & \\
\cline { 1 - 1 } Adsorbent & & $K_{1}\left(\mathrm{mg} \mathrm{g}^{-1} \mathrm{~min}^{-0.5}\right)$ & $C\left(\mathrm{mg} \mathrm{g}^{-1}\right)$ & $R^{2}$ \\
\hline $\mathrm{NiFe}_{2} \mathrm{O}_{4}-\mathrm{SiO}_{2}$ & 1.1570 & -0.075 & 0.98 \\
$\mathrm{MgFe}_{2} \mathrm{O}_{4}-\mathrm{SiO}_{2}$ & 0.8422 & -0.082 & 0.97 \\
$\mathrm{COFe}_{2} \mathrm{O}_{4}-\mathrm{SiO}_{2}$ & 0.8811 & -0.109 & 0.94 \\
$\mathrm{SiO}_{2}$ & 0.6146 & -0.042 & 0.96
\end{tabular}

model fuel. Table 2 presents data regarding the comparison of several adsorbents used by batch tests for desulfurization.

\subsection{Adsorption mechanism}

Thiophene, dibenzothiophene (DBT) and its their alkyl derivatives are the most common sulfur containing organic compounds with strong aromatic ring stability. According to the literature, a probable mechanism for the adsorption of DBT on nanocomposites can be explained by three main factors. First, the size of DBT molecule is closer to that of the adsorbents pores, which allows it to be preferably trapped into the adsorbent. The second factor is the higher dipole moment, molar mass and aromaticity of DBT, which lead to stronger van der Waals interactions with the adsorbents. The third factor is the higher basicity of DBT and its stronger acid-base interaction with ferrite (Lewis acid) on the adsorbent surface. ${ }^{32}$

\subsection{Kinetic study}

The adsorption kinetics was evaluated to obtain the data related to the adsorption rate of refractory sulfur compounds. To this end, PFO and pseudo-second order (PSO) and intraparticle diffusion models were suggested to study the experimental results. Thus, PFO and PSO equations were applied given that the computed concentration equals the surface concentration. ${ }^{33}$ The PFO rate of the Lagergren model ${ }^{34}$ was presented by eqn (2) as follows:

$$
\operatorname{Ln}\left(q_{\mathrm{e}}-q\right)=\operatorname{Ln} q_{\mathrm{e}}-K_{1} t
$$

where $q\left(\mathrm{mg} \mathrm{g}^{-1}\right)$ and $K_{1}\left(\mathrm{~min}^{-1}\right)$ denote the amount of the adsorbed DBT $\left(\mathrm{mg} \mathrm{g}^{-1}\right)$ at time ( $\left.\mathrm{min}\right)$ and the rate constant for the PFO kinetic, respectively. Furthermore, $q_{\mathrm{e}}\left(\mathrm{mg} \mathrm{g}^{-1}\right)$ represents the equilibrium quantity of the adsorbed sulfur at time, which can be obtained by extrapolating the experimental results. Accordingly, extrapolation was achieved by fitting the experimental results to eqn (3) by the Origin software from the Origin Lab Crop:

$$
q=a_{0}+a_{1}\left(1-\exp \left(-\frac{t}{\tau_{1}}\right)\right)+a_{2}\left(1-\exp \left(-\frac{t}{\tau_{2}}\right)\right)
$$

where $a_{0}, a_{1}, a_{2}$, and $\tau_{2}$ are considered as mathematically calculated constants. A straight line of $\operatorname{Ln}\left(q_{\mathrm{e}}-q\right)$, eqn (2), vs. $t$ (Fig. 5a) is employed to calculate $q_{\mathrm{e}}$ and $K_{1}$. The PSO kinetic models are described by eqn (4):

$$
r_{q}=K_{2}\left(q_{e}-q\right)^{2}=\frac{\mathrm{d} q}{\mathrm{~d} t}
$$

Table 4 Langmuir and Freundlich adsorption isotherm parameters

\begin{tabular}{ll}
\hline Langmuir isotherm constant & Freundlich isotherm constant \\
\hline$Q_{\mathrm{m}}=0.94$ & - \\
$K_{1}=13$ & $n=2.93$ \\
$R_{1}=3 \times 10^{-4}$ & $K_{\mathrm{F}}=0.187$ \\
$R^{2}=0.95$ & $R^{2}=0.94$
\end{tabular}



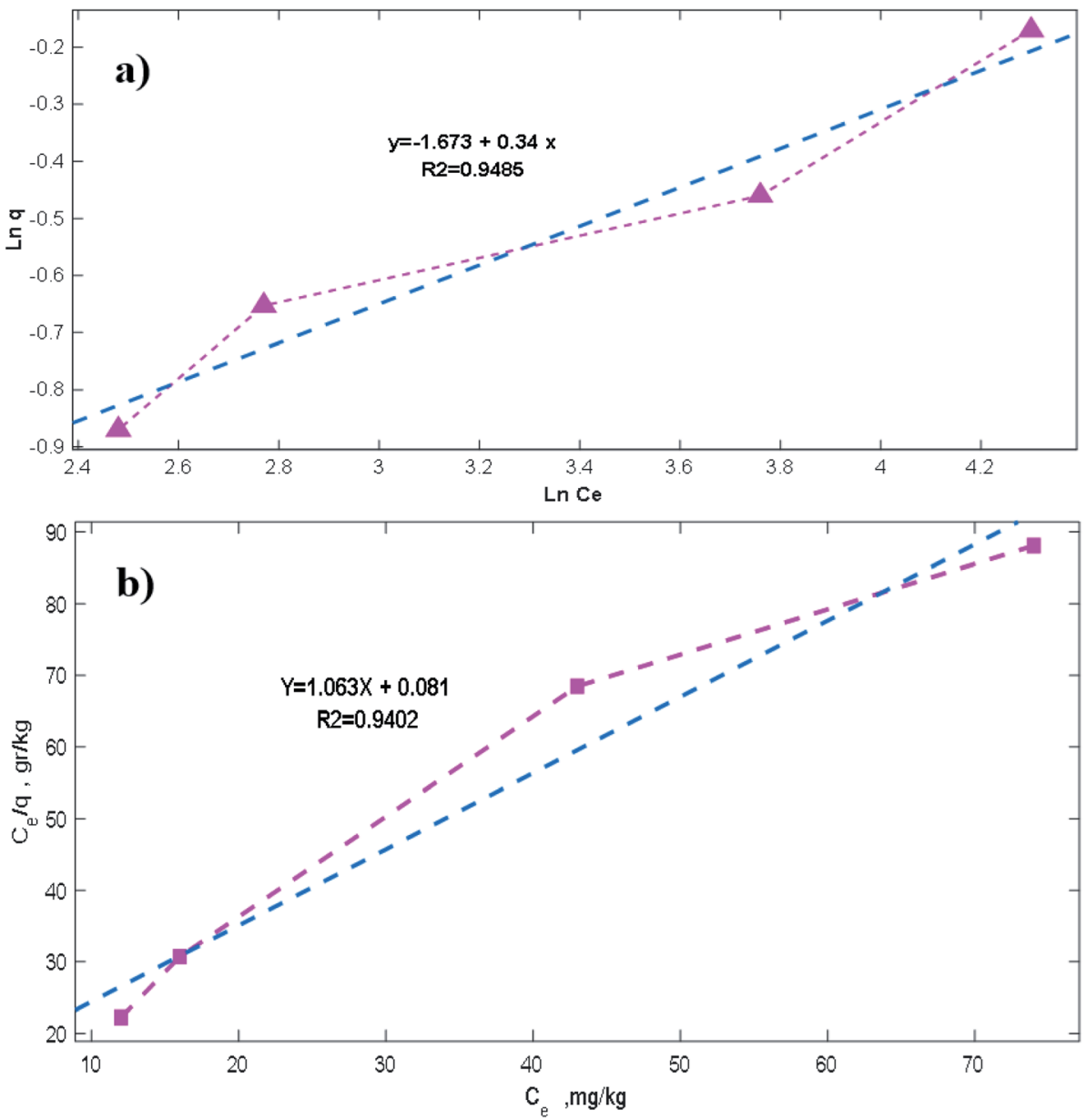

Fig. 6 Results of equilibrium analysis, (a) Langmuir model and (b) Freundlich model.

Table 5 Levels of factors in response surface design

\begin{tabular}{llll} 
Factors & Variable & Low level $(-1)$ & High level $(+1)$ \\
\hline Mass of adsorbent $(\mathrm{g})$ & $M$ & 3 & 7 \\
Time (min) & $t$ & 15 & 50
\end{tabular}

where $K_{2}\left(\mathrm{~g} \mathrm{mg}^{-1} \mathrm{~min}^{-1}\right)$ indicates the rate constant of PSO adsorption. ${ }^{35}$

$$
q=K_{i} t^{0.5}+c
$$

the terms $q_{\mathrm{e}}$ and $K_{2}$ were proposed by graphing $\frac{t}{q} v s . t$ (Fig. 5b).

Furthermore, the intraparticle diffusion model can kinetically explain the adsorption. ${ }^{36}$

Where $q\left(\mathrm{mg} \mathrm{g}^{-1}\right)$ and $K_{i}\left(\mathrm{~g} \mathrm{~g}^{-1} \mathrm{~min}^{-0.5}\right)$ are the amount of the total adsorbed sulfur at time (min) and the intraparticle diffusion rate constant, respectively. The plot of $q_{t}$, eqn (5), vs. $t^{1 /}$ 2 is illustrated in Fig. 5c. Moreover, Table 3 provides the correlation coefficient $\left(R^{2}\right)$ of PFO and PSO adsorption kinetic models and the intraparticle diffusion model. The $R^{2}$ values for

Table $6 \quad 2^{2}$ Response surface design

\begin{tabular}{|c|c|c|c|c|c|c|c|}
\hline Experimental run & Coded time & $\begin{array}{l}\text { Coded mass of } \\
\text { adsorbent }\end{array}$ & $\begin{array}{l}\text { Uncoded } \\
\text { time }\end{array}$ & $\begin{array}{l}\text { Uncoded mass } \\
\text { of adsorbent }\end{array}$ & $\begin{array}{l}Y \\
\text { (experimental) }\end{array}$ & $\begin{array}{l}Y \\
\text { (predicted) }\end{array}$ & Residual \\
\hline 1 & 1 & -1 & 50.00 & 3.00 & 0.713 & 0.735 & -0.022 \\
\hline 3 & -1 & 1 & 15.00 & 7.00 & 0.450 & 0.420 & 0.029 \\
\hline 4 & 1.41 & 0 & 57.24 & 5.00 & 0.640 & 0.630 & 0.006 \\
\hline 5 & 1 & 1 & 50.00 & 7.00 & 0.520 & 0.500 & 0.014 \\
\hline 8 & 0 & 1.41 & 32.50 & 7.82 & 0.386 & 0.415 & -0.020 \\
\hline 9 & -1 & -1 & 15.00 & 3.00 & 0.660 & 0.667 & -0.007 \\
\hline
\end{tabular}


Table 7 Estimated regression coefficient for the model

\begin{tabular}{lllll}
\hline Term & Coefficient & SE coefficient & S & $P$ \\
\hline Constant & 0.528 & 0.033 & 15.96 & 0.001 \\
$t$ & 0.038 & 0.011 & 3.24 & 0.048 \\
$m$ & -0.110 & 0.011 & -10.2 & 0.002 \\
$t \times t$ & 0.025 & 0.019 & 1.33 & 0.275 \\
$m \times m$ & 0.028 & 0.019 & 1.46 & 0.241 \\
$t \times m$ & 0.004 & 0.016 & 0.25 & 0.814 \\
& & & &
\end{tabular}

the PFO model well match the obtained experimental results compared to the PSO model, indicating that the adsorption is not a second-order reaction and confirming the occurrence of the intraparticle diffusion. However, the data in Fig. 5c shows three regions with different slopes for each plot, indicating three various stages for the adsorption process. The first region (a $0-5$ time interval) is attributed to the external surface adsorption. Additionally, the second region (a 5-20 time interval) implies that the intraparticle diffusion is the rate controlling step. Finally, the intraparticle diffusion decreased upon reaching the equilibrium conditions. As shown, the linear plot fails to pass the origin, which shows that another mechanism may be accompanied by the intraparticle diffusion model. ${ }^{1}$

\subsection{Adsorption isotherms}

The DBT adsorption on the $\mathrm{NiFe}_{2} \mathrm{O}_{4}-\mathrm{SiO}_{2}$ nanocomposite was investigated in batch mode. In addition, the isotherms helped to
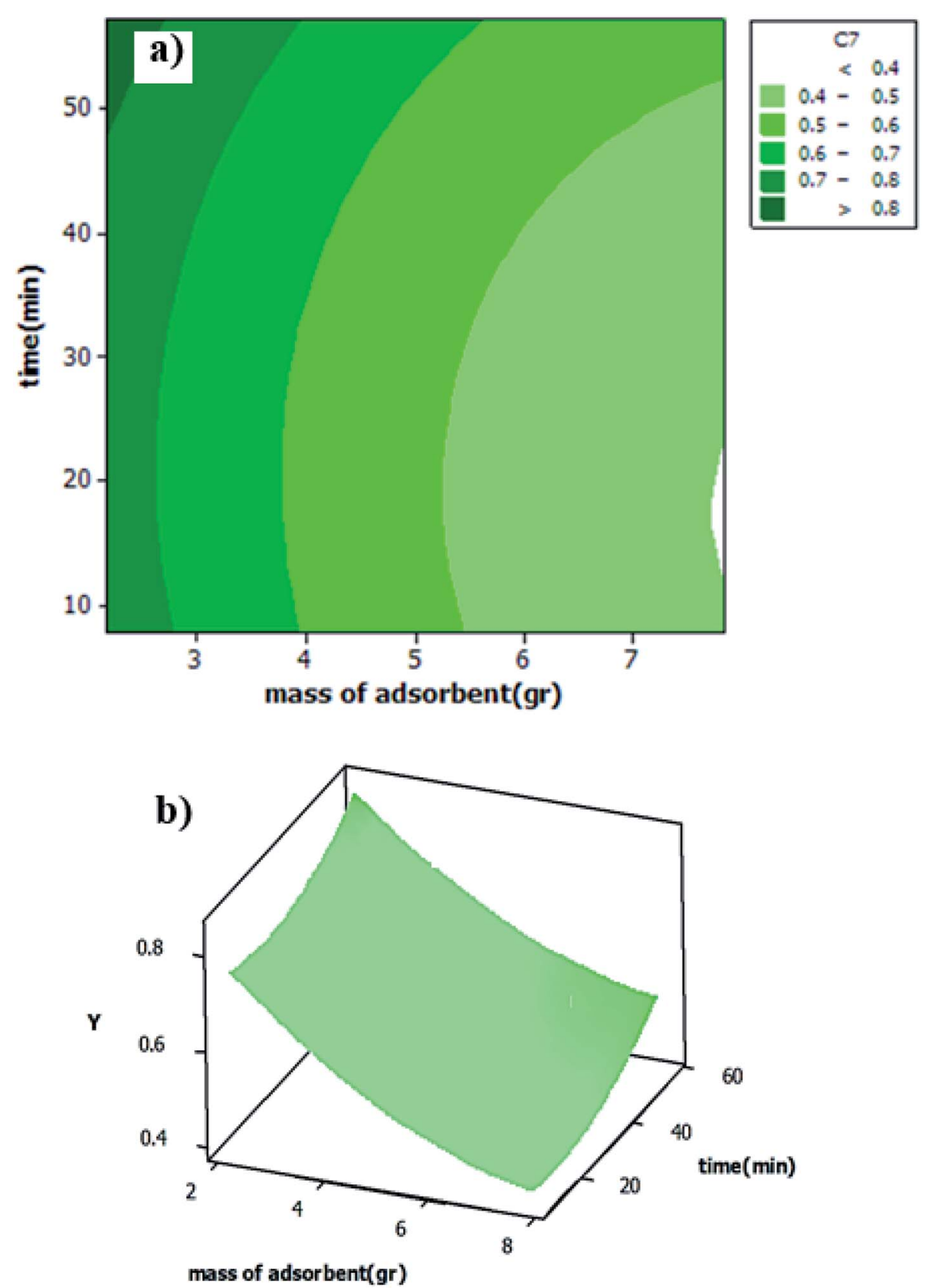

Fig. 7 (a) Surface plot of interactive effect of $t$ and $m$ on $y$. (b) Contour plot of $y v s$. $t$ and $m$. 
determine the mechanism of adsorption. The effect of $\mathrm{NiFe}_{2} \mathrm{O}_{4}-\mathrm{SiO}_{2}$ dosage on the sulfur removal percentage was then studied using DBT concentration of $200 \mathrm{mg} \mathrm{l}^{-1}$. The adsorbent concentration ranged from 3 to $9 \mathrm{~g}$ per $50 \mathrm{ml}$ for the liquid model fuel. Furthermore, two various isotherms (i.e., Langmuir and Freundlich) were used to fit the experimental data to achieve the equilibrium characterization of the ADS process. ${ }^{37}$ Linear expression of the Langmuir isotherm model is as follows (Table 4):

$$
\frac{C_{\mathrm{e}}}{q}=\frac{1}{q_{\mathrm{m}} K_{\mathrm{L}}}+\frac{C_{\mathrm{e}}}{q_{\mathrm{m}}}
$$

where $q_{\mathrm{e}}\left(\mathrm{mg} \mathrm{g}^{-1}\right)$ and $C_{\mathrm{e}}\left(\mathrm{mg} \mathrm{l}^{-1}\right)$ indicate the adsorbed and unadsorbed sulfur concentrations in the equilibrium conditions, respectively. Furthermore, $K_{\mathrm{L}}$ is the Langmuir constant and $q_{\mathrm{m}}$ denotes the maximum adsorbate amount, which forms a complete monolayer on the surface $\left(\mathrm{mg} \mathrm{g}^{-1}\right)$. Likewise, Langmuir constants can be obtained from the slope and intercept of the linear plot of $\frac{C_{\mathrm{e}}}{q_{\mathrm{e}}} v s . C_{\mathrm{e}}$ in Fig. $6 \mathrm{~b} \cdot{ }^{38-40}$ The parameters of the Langmuir isotherm are presented in Table 5 . In addition, the separation factor, $R_{\mathrm{L}}$, which is related to the adsorption favorability, ${ }^{\mathbf{4 1}}$ is obtained as follows:

$$
R_{\mathrm{L}}=\frac{1}{1+K_{\mathrm{L}} C_{0}}
$$

where $K_{\mathrm{L}}$ and $\mathrm{C}_{0}$ represent the Langmuir rate constant and the highest initial concentration, respectively. The values of $R_{\mathrm{L}}>1$ and $R_{\mathrm{L}}=1$, as well as $0<R_{\mathrm{L}}<1$ and $R_{\mathrm{L}}=0$ indicate unsuitable, linear, suitable, and irreversible processes, respectively. ${ }^{\mathbf{4 2 - 4 6}}$ Moreover, the Freundlich model relies on the assumption that there exist heterogeneous adsorptive energies on the surface of the adsorbent. This isotherm was considered as the multi-layer adsorption with possible physisorption and chemisorption. ${ }^{\mathbf{7}}$ The linear expression of the Freundlich isotherm model is expressed as follows: $:^{33,48}$

$$
\operatorname{Ln} q_{\mathrm{e}}=\operatorname{Ln} K_{\mathrm{F}}+\frac{1}{n} \operatorname{Ln} C_{\mathrm{e}}
$$

where $K_{\mathrm{F}}$ is the Freundlich constant, which demonstrates the binding energy of the adsorbent, and $n$ denotes the heterogeneity factor, which estimates the deviation from linear adsorption. Accordingly, adsorption is suitable when the $n$ values of 1-10 are obtained for the process. Additionally, plotting $\operatorname{Ln} q_{\mathrm{e}} v s$. Ln $C_{\mathrm{e}}$ leads to a straight line with the slope and intercept values of $\frac{1}{n}$ and $K_{\mathrm{F}}$,
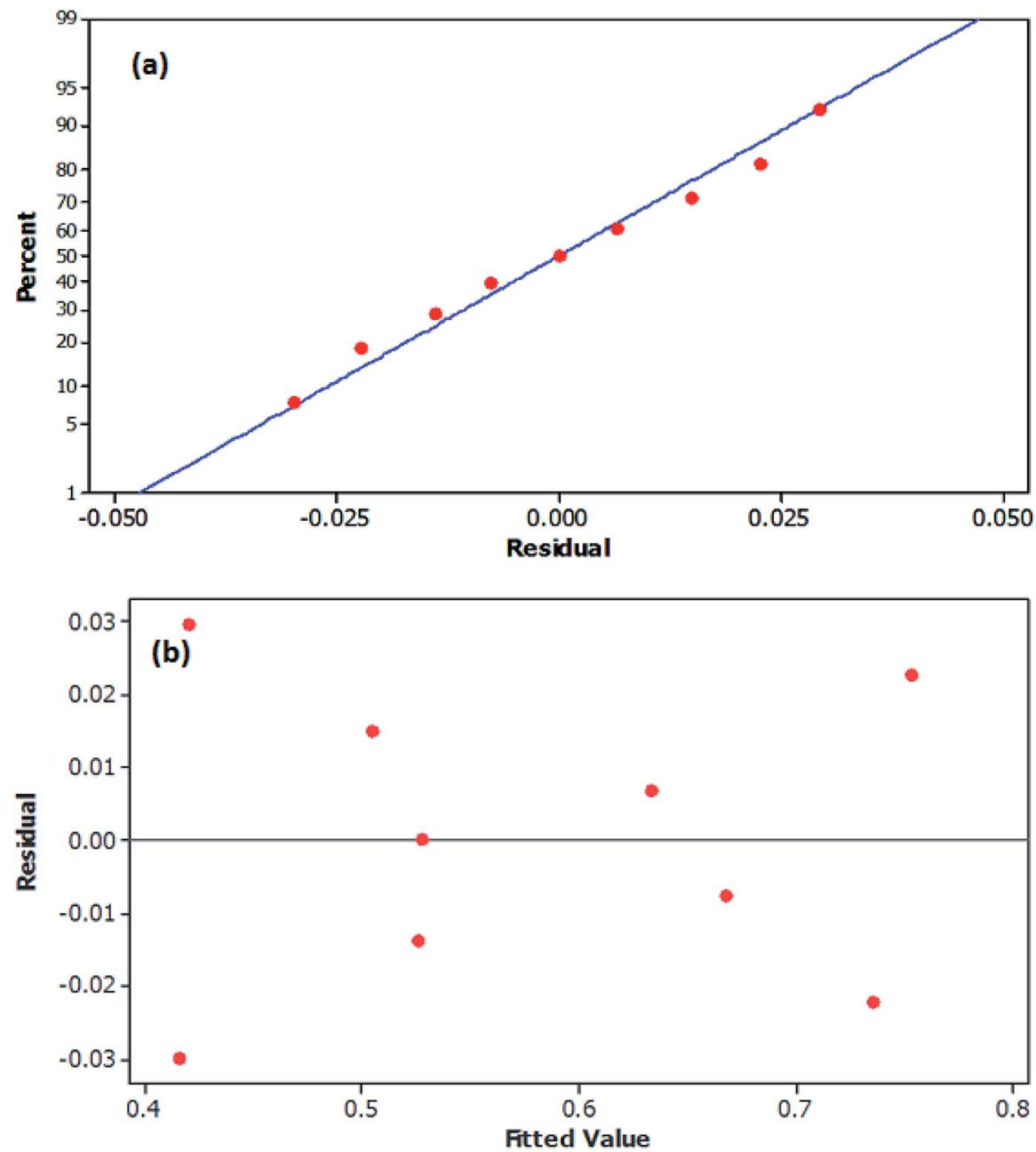

Fig. 8 (a) Normal probability plot of residuals (b) plot of residual versus predicted values. 
respectively. ${ }^{38,40,43}$ Based on the data in Table 5 , the values of $R_{\mathrm{L}}$ and $\frac{1}{n}$ are in the range of $0-1$, which confirms the desirability of sulfur adsorption on the $\mathrm{NiFe}_{2} \mathrm{O}_{4}-\mathrm{SiO}_{2}$. Finally, correlation coefficients $\left(R^{2}\right)$, along with the data in Fig. 6 indicate that the Langmuir model fits well with the equilibrium data.

\subsection{Statistical study}

Central composite design is a multi-variable of the response surface design, which is used to evaluate the effects of process variables including the mass of adsorbent and time on sulfur removal percentage (response), facilitating the fitting of the data with the quadratic model. The maximum and minimum levels of the adsorbent dosage were $3-9 \mathrm{~g}$, which were coded -1 and +1 , respectively. In addition, the corresponding levels of the time were 15-50 min, which were coded -1 and +1 , respectively. ${ }^{49}$ To specify the desired operating conditions of sulfur adsorption by $\mathrm{NiFe}_{2} \mathrm{O}_{4}-\mathrm{SiO}_{2}$, this process was conducted under different conditions (Table 5). The experimental data were then evaluated using Minitab 18 (trial version) including ANOVA in order to identify the interaction between the processed variables and responses. ${ }^{51,52}$ The nine experiments, including four axial and four factorial points, and one replication of the central points, were performed at five levels.
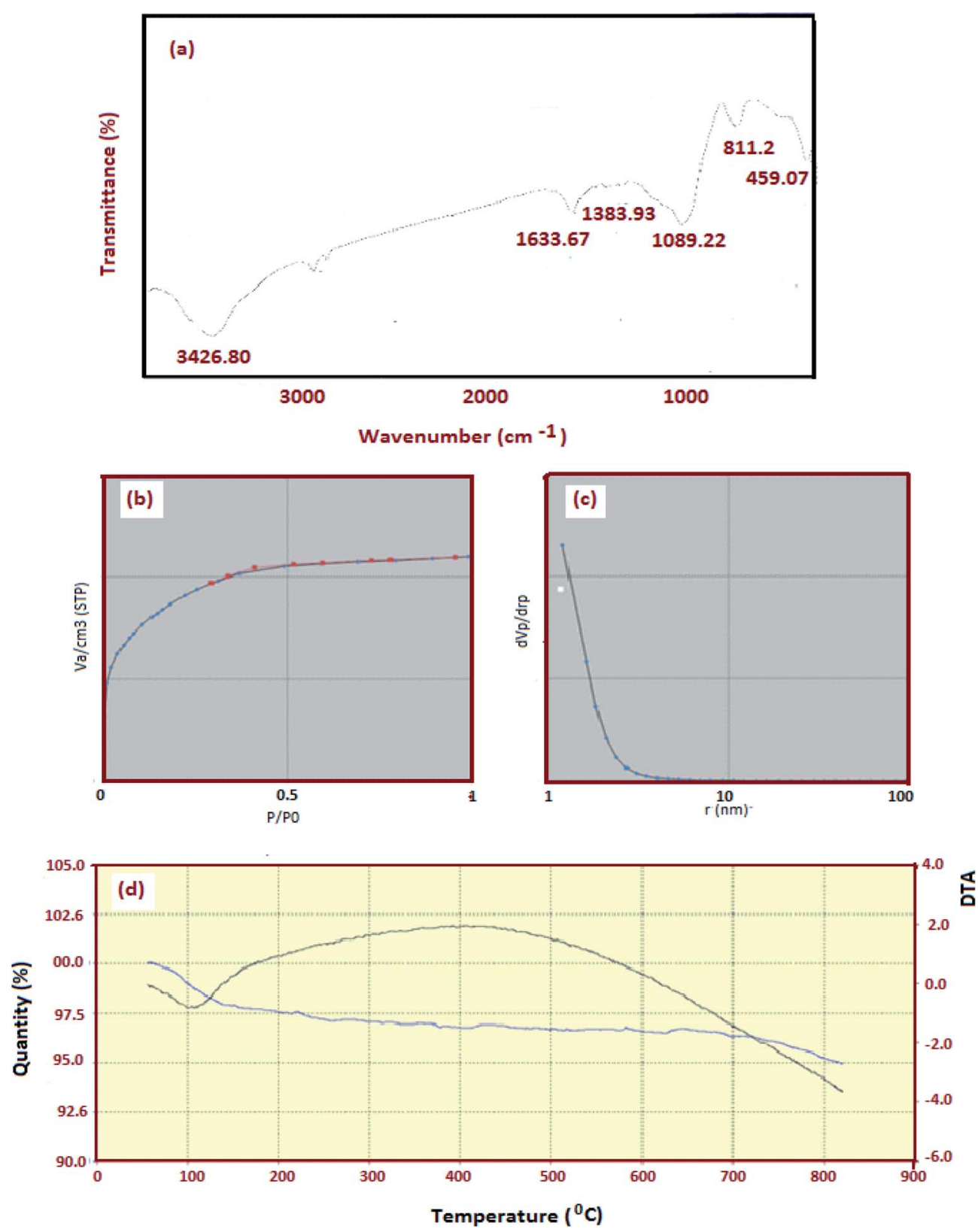

Fig. 9 (a) FT-IR spectrum of obtained $\mathrm{NiFe}_{2} \mathrm{O}_{4}-\mathrm{SiO}_{2}$ (b) $\mathrm{N}_{2}$ adsorption-desorption isotherm (c) pore size and (d) $\mathrm{TGA}_{\mathrm{A}}$ curve of $\mathrm{NiFe}_{2} \mathrm{O}_{4}-\mathrm{SiO}_{2}$ nanocomposite. 


\subsection{Optimization of conditions for the ADS process}

Furthermore, the optimization and effect of two parameters (i.e., mass of adsorbent and time) on the sulfur removal percentage were studied by employing CCD. Based on the CCD, the regression equation to describe a mathematical correlation between the sulfur removal percentage $(Y)$ and the selected parameters (i.e., adsorbent dosage and constant time) is expressed by the following second-order polynomial equation:

$$
\begin{aligned}
Y(\text { predicted })= & 0.528+0.038 t-0.11 M+0.025 t^{2}+0.028 M^{2} \\
& +0.004 M \times t
\end{aligned}
$$

Table 6 provides the predicted values obtained by applying the coded values of the selected parameters in eqn (9); namely, the quadratic equation. Based on the difference between the predicted and experimental values, residual values are acceptable. According to eqn (9), negative signs show antagonistic effects while positive ones indicate synergistic effects. Therefore, the amount of the adsorbed sulfur increased with time whereas the increase in adsorbent mass decreased this response. According to Table 7, the linear terms of the two variables (i.e., adsorbent dosage, and time) are statistically significant $(p<0.05)$. The interaction between the quadratic terms can be ignored based on their high $p$-value $(p<$ $0.05)$. The results showed a coefficient of determination of $R^{2}=$ 0.975 . In addition, an $R^{2}$ of over 0.875 represents a favorable value for model validation.

\subsection{Response surface and contour plots}

Three dimensional (3D) surface and 2D contour plots are the graphs, which can be used to investigate the interactive effects of the selected factors on the removal efficiency of DBT from the model fuel. According to surface and contour plots (Fig. 7a and b), the adsorbent dosage of $7.82 \mathrm{~g} \mathrm{l}^{-1}$ and contact time of $32.5 \mathrm{~min}$ were selected as the optimal values. Based on the results obtained, the predicted sulfur removal percentage $(0.4158 \%)$ under these conditions is approximately similar to the experimental amount of $0.386 \%$. Moreover, Fig. 8a displays the normal probability plot of residuals used to examine the normal distribution of standard deviations. As shown, the majority of residuals follow a straight line with minimal variations from their directions. Fig. 8b depicts the plot of the predicted responses against residuals. Based on the data, all the points
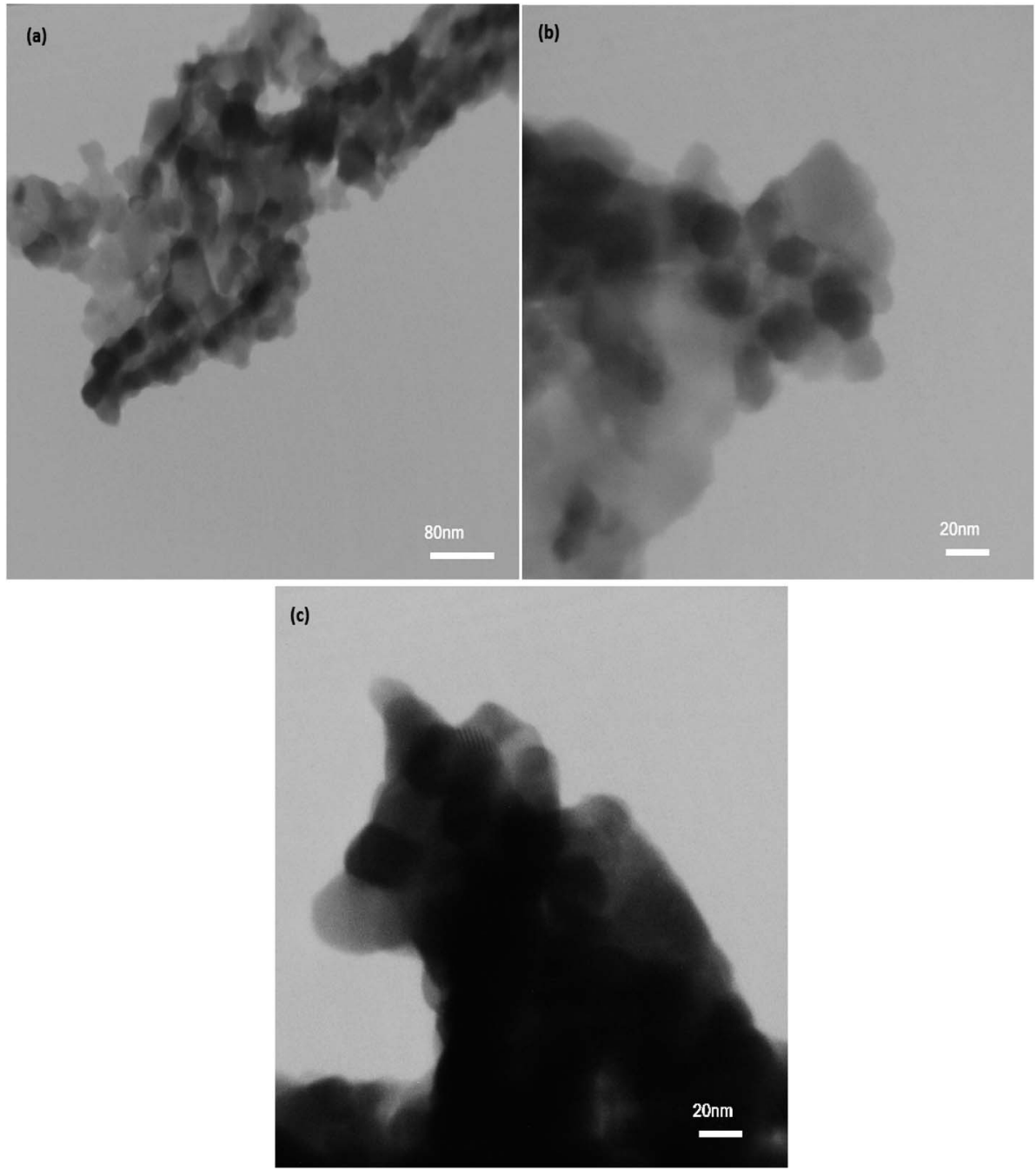

Fig. $10 \mathrm{TEM}$ images from $\mathrm{NiFe}_{2} \mathrm{O}_{4}-\mathrm{SiO}_{2}$ in two different scales (a) $80 \mathrm{~nm}$ (b and c) $20 \mathrm{~nm}$. 


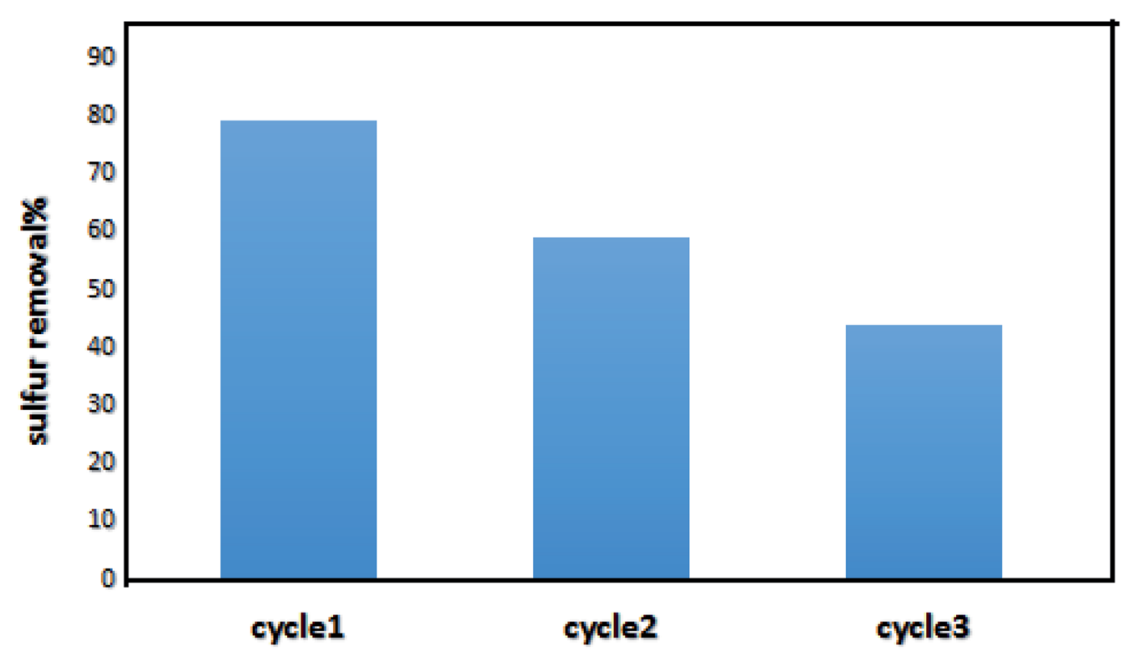

Fig. 11 Sulfur removal with regenerated $\mathrm{NiFe}_{2} \mathrm{O}_{4}-\mathrm{SiO}_{2}$.

in the experimental runs are randomly distributed around the average of the response variable, indicating that the proposed model is sufficient. Eventually, the sufficiency of the model in Fig. 8 was studied by examining the residuals, as described by Chieng et al. ${ }^{50}$

The specific surface area of $\mathrm{NiFe}_{2} \mathrm{O}_{4}-\mathrm{SiO}_{2}$ nanocomposite was determined using Brunauer-Emmett-Teller (BET).

Fig. 9a shows the FT-IR spectra of nickel ferrite-silica nanocomposites (sample 3). The important peaks observed at $3426.80,1633.67$ and $1089.29 \mathrm{~cm}^{-1}$ correspond to the asymmetric stretching and bending modes of $\mathrm{O}-\mathrm{H}, \mathrm{Si}=\mathrm{O}$ and $\mathrm{C}-\mathrm{O}$, respectively. Two intense bands at 811.2 and $459.07 \mathrm{~cm}^{-1}$ are attributed to the stretching vibration of $\mathrm{Fe}-\mathrm{O}$ and $\mathrm{Ni}-\mathrm{O}$, respectively. Fig. $9 \mathrm{~b}$ shows $\mathrm{N}_{2}$ adsorption/desorption isotherm. The nature of the isotherm confirmed the presence of mesoporous materials with a BET surface area of $501.47 \mathrm{~m}^{2} \mathrm{~g}^{-1}$. The micropore diameter was determined to be $2.17 \mathrm{~nm}$ using $\mathrm{BJH}$ method (Fig. 9c). Fig. 9d shows the TG and DTA curves of $\mathrm{NiFe}_{2} \mathrm{O}_{4}-\mathrm{SiO}_{2}$ nanocomposite. The thermal behavior indicates a single step decomposition and thus, the formation of the oxide takes place by auto-combustion mechanism. Beyond $200{ }^{\circ} \mathrm{C}$, the mass decreases up to $800{ }^{\circ} \mathrm{C}$ due to the dehydroxylation of silica. A drastic weight loss (about $80 \%$ ) can be observed at about $300{ }^{\circ} \mathrm{C}$ corresponding to a sharp and intense exothermic peak in the DTA curves centered at 400 for the iron polymer gel. This behavior shows that the decomposition of the gel occurs suddenly as a single step.

Information on nanocrystal size and dispersion within the silica matrix was obtained by transmission electron microscopy. Fig. 10 shows the TEM images in two different scales. The bright field images exhibit the porous texture of silica. On the other hand, the presence of nanocrystals between 20 and $80 \mathrm{~nm}$ is observed in dark field mode. Based on the high porosity and homogeneity of the nanocomposite, the nanocrystals are well distributed and no aggregates are observed.

\subsection{Regeneration experiments}

Adsorbent recyclability is a significant parameter for industrial applications. As depicted in Fig. $3 \mathrm{a}, \mathrm{NiFe}_{2} \mathrm{O}_{4}$ shows the best performance among all adsorbents. Therefore, $9 \mathrm{~g}$ of this adsorbent were used per $50 \mathrm{ml}$ of the model fuel for adsorptionregeneration process. The applied adsorbent was regenerated by calcination in the air at temperature of $500{ }^{\circ} \mathrm{C}$ for $2 \mathrm{~h}$. As shown in Fig. 11, the adsorbent can be used in three cycles of the adsorption-regeneration process. In addition, in cycle 3 , the removal efficiency has reached below $50 \% .^{54-61}$

\section{Conclusions}

$\mathrm{AFe}_{2} \mathrm{O}_{4}-\mathrm{SiO}_{2}(\mathrm{~A}=\mathrm{Ni}, \mathrm{Mg}$, and $\mathrm{Co})$ nanocomposites were synthesized by an auto-combustion sol-gel method and then used for DBT adsorption from the model fuel. According to the results, $\mathrm{NiFe}_{2} \mathrm{O}_{4}-\mathrm{SiO}_{2}$ nanocomposites demonstrated the best performance in comparison to other compounds. The adsorption of DBT on $\mathrm{NiFe}_{2} \mathrm{O}_{4}-\mathrm{SiO}_{2}$ was explained by the Langmuir isotherm model and the experimental data indicated the closest match with the PFO kinetic. Moreover, the intraparticle diffusion revealed that other mechanisms may play a role in the adsorption process, along with the intraparticle diffusion. Based on the statistical investigations, the optimal conditions for ADS were adsorbent dosage of $7.82 \mathrm{~g}$ per $50 \mathrm{ml}$ of the model fuel and a contact time of $32 \mathrm{~min}$. However, selecting suitable adsorbents is regarded an essential challenge in ADS. Thus, further investigations are required on active metals as adsorbents for removing sulfur from hydrocarbon fuels.

\section{Conflicts of interest}

The authors declare that there are no conflicts of interest regarding the publication of this manuscript.

\section{Acknowledgements}

Authors are grateful to the council of Semnan University, Iran National Science Foundation; INSF (97017837) and University of Kashan for supporting this work by Grant No. (159271/ V1). 


\section{References}

1 T. Saleh, Simultaneous adsorptive desulfurization of diesel fuel over bimetallic nanoparticles loaded on activated carbon, J. Cleaner Prod., 2018, 172, 2123-2132.

2 M. Ahmadi, M. Mohammadian, M. R. Khosravi-Nikou and A. Baghban, Experimental, kinetic, and thermodynamic studies of adsorptive desulfurization and denitrogenation of model fuels using novel mesoporous materials, $J$. Hazard. Mater., 2019, 374, 129-139.

3 M. Muzic, K. Sertic-Bionda and Z. Gomzi, Kinetic and statistical studies of adsorptive desulfurization of diesel fuel on commercial activated carbons, Chem. Eng. Technol, 2008, 31(3), 355-364.

4 C. Song, An overview of new approaches to deep desulfurization for ultra-clean gasoline, diesel fuel and jet fuel, Catal. Today, 2003, 86(1-4), 211-263.

5 I. V. Babich and J. A. Moulijn, Science and technology of novel processes for deep desulfurization of oil refinery streams: a review

6 H. Li, W. Zhu, S. Zhu, J. Xia, Y. Chang, W. Jiang, M. Zhang, Y. Zhou and $\mathrm{H}$. Li, The selectivity for sulfur removal from oils: an insight from conceptual density functional theory, Reaction Engineering, Kinetics and Catalysis, 2016, 62(6), 2087-2100.

7 Y. Liu, F. Guo, J. Hu, S. Zhao, H. Liu and Y. Hu, Screening of desulfurization adsorbent in metal-organic frameworks: a classical density functional approach, Chem. Eng. Sci., 2015, 137, 170-177.

8 D. Zhang, H. Tao, C. Yao and Z. Sun, Effects of residence time on the efficiency of desulfurization and denitrification in the bubbling reactor, Chem, 2017, 174, 203-221.

9 L. Dong, G. Miao, X. Ren, N. Liao, A. W. Anjum, Z. Li and J. Xiao, Desulfurization Kinetics and Regeneration of Silica Gel-Supported $\mathrm{TiO}_{2}$ Extrudates for Reactive Adsorptive Desulfurization of Real Diesel, Ind. Eng. Chem. Res., 2020, 59(21), 10130-10141.

10 M. Muzic, K. Sertic-Bionda and T. Adzamic, The application of theoretical solutions to the differential mass balance equation for modeling of adsorptive desulfurization in a packed bed adsorber, Chem. Eng. Process., 2011, 50(4), 409-416.

11 X. Ma, K. Sakanishi and I. Mochida, Hydrodesulfurization reactivities of various sulfur compounds in diesel fuel, Ind. Eng. Chem. Res., 1994, 33(2), 218-222.

12 A. J. Hernández-Maldonado, F. H. Yang, G. Qi and R. T. Yang, Desulfurization of transportation fuels by $\pi$ complexation sorbents: $\mathrm{Cu}(\mathrm{I})-, \mathrm{Ni}(\mathrm{II})-$, and $\mathrm{Zn}(\mathrm{II})$-zeolites, Appl. Catal., B, 2005, 56(1-2), 111-126.

13 J. Zou, Y. Lin, S. Wu, M. Wu and C. Yang, Construction of bifunctional 3-D ordered mesoporous catalyst for oxidative desulfurization, Sep. Purif. Technol., 2021, 264, 118434.

14 J. Zou, Y. Lin, S. Wu, Y. Hong and C. Yang, Molybdenum Dioxide Nanoparticles Anchored on Nitrogen-Doped Carbon Nanotubes as Oxidative Desulfurization Catalysts: Role of Electron Transfer in Activity and Reusability, Adv. Funct. Mater., 2021, 2100442.
15 M. Muzic, Z. Gomzi and K. Sertic-Bionda, Modeling of the Adsorptive Desulfurization of Diesel Fuel in a Fixed-Bed Column, Chem. Eng. Technol., 2010, 33(7), 1137-1145.

16 J. Xiao, X. Wang, M. Fujii, Q. Yang and C. Song, A novel approach for ultra-deep adsorptive desulfurization of diesel fuel over $\mathrm{TiO}_{2}-\mathrm{CeO}_{2} / \mathrm{MCM}-48$ under ambient conditions, AIChE J., 2013, 59(5), 1441-1445.

17 Y. Shi, X. Zhang, L. Wang and G. Liu, MOF-derived porous carbon for adsorptive desulfurization, AIChE J., 2014, 60(8), 2747-2751.

18 D. Jha, M. B. Haider, R. Kumar, W. G. Shim and B. Marriyappan Sivagnanam, Batch and Continuous Adsorptive Desulfurization of Model Diesel Fuels Using Graphene Nanoplatelets, J. Chem. Eng. Data, 2020, 65(4), 2120-2132.

19 F. Pola-Albores, K. Zambrano-Solís, E. Ríos-Valdovinos, J. Conde-Díaz, H. Vilchis-Bravo, J. A. Reyes-Nava, J. Pantoja-Enríquez and J. Moreira-Acosta, $\mathrm{ZnO}$ and $\mathrm{Cu}-$ based adsorbents for biogas desulfurization at room temperature, J. Mater. Sci.: Mater. Electron., 2018, 9, 1559715603.

20 X. Chen, K. Zhu, M. A. Ahmed, J. Wang and C. Liang, Mössbauer spectroscopic characterization of ferrites as adsorbents for reactive adsorption desulfurization, Chin. J. Catal., 2016, 37(5), 727-734.

21 L. Zhao, X. Li, Q. Zhao, Z. Qu, D. Yuan, S. Liu and G. Chen, Synthesis, characterization and adsorptive performance of $\mathrm{MgFe}_{2} \mathrm{O}_{4}$ nanospheres for $\mathrm{SO}_{2}$ removal, Hazard. Mater., 2010, 184(1-3), 704-709.

22 A. G. Georgiadis, N. D. Charisiou and M. A. Goula, Removal of hydrogen sulfide from various industrial gases: a review of the most promising adsorbing materials, J. Catal., 2020, 10(5), 521.

23 S. Mendiratta and A. A. Ali, Recent Advances in Functionalized Mesoporous Silica Frameworks for Efficient Desulfurization of Fuels, J. Nanomater., 2020, 10(6), 1116.

24 N. D. Charisiou, L. Tzounis, V. Sebastian, S. J. Hinder, M. A. Baker, K. Polychronopoulou and M. A. Goula, Investigating the correlation between deactivation and the carbon deposited on the surface of $\mathrm{Ni} / \mathrm{Al}_{2} \mathrm{O}_{3}$ and $\mathrm{Ni} / \mathrm{La}_{2} \mathrm{O}_{3}-$ $\mathrm{Al}_{2} \mathrm{O}_{3}$ catalysts during the biogas reforming reaction, Appl. Surf. Sci., 2019, 474, 42-56.

25 M. S. Shah, M. Tsapatsis and J. I. Siepmann, Hydrogen sulfide capture: from absorption in polar liquids to oxide, zeolite, and metal-organic framework adsorbents and membranes, Chem. Rev., 2017, 117(14), 9755-9803.

26 A. Hadela, M. Lakić, M. Potočnik, M. Košak, A. Gutmaher and A. Lobnik, Novel reusable functionalized magnetic cobalt ferrite nanoparticles as oil adsorbents, Adsorpt. Sci. Technol., 2020, 38(5-6), 168-190.

27 Y. S. Hong, K. R. Sin, J. S. Pak, C. J. Kim and B. S. Liu, Kinetic analysis of $\mathrm{H} 2 \mathrm{~S}$ removal over mesoporous $\mathrm{Cu}-\mathrm{Mn}$ mixed oxide/SBA-15 and La-Mn mixed oxide/KIT-6 sorbents during hot coal gas desulfurization using the deactivation kinetics model, Energy Fuels, 2017, 31(9), 9874-9880.

28 S. Mandizadeh, M. Sadri and M. Salavati-Niasari, Mechanosynthesis and characterization $\mathrm{AFe}_{2} \mathrm{O}_{4}$ (A: Ni, Cu, 
Zn)-activated carbon nanocomposite as an effective adsorbent for removal dodecanethiol, Microporous Mesoporous Mater., 2018, 262, 13-22.

29 M. Moradi, R. Karimzadeh and E. S. Moosavi, Modified and ion exchanged clinoptilolite for the adsorptive removal of sulfur compounds in a model fuel: new adsorbents for desulfurization, J. Fuels, 2018, 217, 467-477.

30 M. A. Ahmed, E. García, L. Alonso and J. M. Palacios, A MS, SEM-EDX and XRD study of Ti or Cu-doped zinc ferrites as regenerable sorbents for hot coal gas desulfurization, Appl. Surf. Sci., 2000, 156(1-4), 115-124.

31 H. Parab, S. Joshi, N. Shenoy, A. Lali, U. S. Sarma and M. Sudersanan, Determination of kinetic and equilibrium parameters of the batch adsorption of $\mathrm{Co}(\mathrm{II}), \mathrm{Cr}(\mathrm{III})$ and Ni(II) onto coir pith, Process Biochem., 2006, 41(3), 609-615.

32 M. K. Nazal, M. Khaled, M. A. Atieh, I. H. Aljundi, G. A. Oweimreen and A. M. Abulkibash, The nature and kinetics of the adsorption of dibenzothiophene in model diesel fuel on carbonaceous materials loaded with aluminum oxide particles, Arabian J. Chem., 2019, 12(8), 3678-3691.

33 S. K. Lagergren, About the theory of so-called adsorption of soluble substances, Kungliga Svenska Vetenskapsakademiens Handlingar, 1898, 24, 1-39.

34 Y. S. Ho and G. McKay, Pseudo-second order model for sorption processes, Process Biochem., 1999, 34(5), 451-465.

35 G. McKay and V. J. Poots, Kinetics and diffusion processes in colour removal from effluent using wood as an adsorbent, $J$. Chem. Technol. Biotechnol., 1980, 30(1), 279-292.

36 K. Y. Foo and B. H. Hameed, Insights into the modeling of adsorption isotherm systems, Chem. Eng. Sci., 2010, 156(1), $2-10$.

37 J. Wen, X. Han, H. Lin, Y. Zheng and W. Chu, A critical study on the adsorption of heterocyclic sulfur and nitrogen compounds by activated carbon: equilibrium, kinetics and thermodynamics, Chem. Eng. J., 2010, 164(1), 29-36.

38 X. Xu, S. Zhang, P. Li and Y. Shen, Equilibrium and kinetics of Jet-A fuel desulfurization by selective adsorption at room temperatures, Fuel, 2013, 111, 172-179.

39 P. Misra, S. Badoga, A. Chenna, A. K. Dalai and J. Adjaye, Denitrogenation and desulfurization of model diesel fuel using functionalized polymer: charge transfer complex formation and adsorption isotherm study, Chem. Eng. Sci., 2017, 325, 176-187.

$40 \mathrm{~J}$. Wang and J. Wei, Selective and simultaneous removal of dibenzothiophene and 4-methyldibenzothiophene using double-template molecularly imprinted polymers on the surface of magnetic mesoporous silica, Mater. Chem., 2017, 5(9), 4651-4659.

$41 \mathrm{C} . \mathrm{H}$. $\mathrm{Wu}$, Adsorption of reactive dye onto carbon nanotubes: equilibrium, kinetics and thermodynamics, J. Hazard. Mater., 2007, 144(1-2), 93-100.

42 R. A. Beygli, N. Mohaghegh and E. Rahimi, Metal ion adsorption from wastewater by $\mathrm{g}-\mathrm{C}_{3} \mathrm{~N}_{4}$ modified with hydroxyapatite: a case study from Sarcheshmeh Acid Mine Drainage, Res. Chem. Intermed., 2019, 45(4), 2255-2268.
43 N. Li, X. Ma, Q. Zha and C. Song, Analysis and comparison of nitrogen compounds in different liquid hydrocarbon streams derived from petroleum and coal, Energy Fuels, 2010, 24(10), 5539-5547.

44 K. R. Hall, L. C. Eagleton, A. Acrivos and T. Vermeulen, Poreand solid-diffusion kinetics in fixed-bed adsorption under constant-pattern conditions, Ind. Eng. Chem. Fundam., 1966, 5(2), 212-223.

$45 \mathrm{~J}$. Wang and J. Wei, Selective and simultaneous removal of dibenzothiophene and 4-methyldibenzothiophene using double-template molecularly imprinted polymers on the surface of magnetic mesoporous silica, J. Mater. Chem. A, 2017, 5(9), 4651-4659.

46 F. O. Okeola and E. O. Odebunmi, Freundlich and Langmuir isotherms parameters for adsorption of methylene blue by activated carbon derived from agro wastes, Adv. Nat. Appl. Sci., 2010, 4(3), 281-289.

47 M. Jiang and F. T. Ng, Adsorption of benzothiophene on Y zeolites investigated by infrared spectroscopy and flow calorimetry, Catal. Today, 2006, 116(4), 530-536.

48 D. S. Aribike, M. A. Usman and M. M. Oloruntoba, Adsorptive desulfurization of diesel using activated sewage sludge: kinetics, equilibrium and thermodynamics studies, Appl. Petrochem. Res., 2019, 1-12.

49 B. Heller, Statistics for experimenters, an introduction to design, data analysis, and model building, ed. G. E. P. Box, W. G. Hunter and J. S. Hunter, John Wiley and Sons, New York, NY, 1986, p. 1978.

50 B. W. Chieng, N. A. Ibrahim and W. W. Yunus, Optimization of tensile strength of poly(lactic acid)/graphene nanocomposites using response surface methodology, Polym.-Plast. Technol. Eng., 2012, 51(8), 791-799.

51 M. Ghaedi, S. Hajati, M. Zare and S. S. Jaberi, Experimental design for simultaneous analysis of malachite green and methylene blue; derivative spectrophotometry and principal component-artificial neural network, RSC Adv., 2015, 5(49), 38939-38947.

52 M. Alimohammady, M. Jahangiri, F. Kiani and H. Tahermansouri, Highly efficient simultaneous adsorption of $\mathrm{Cd}(\mathrm{II}), \mathrm{Hg}$ (II) and $\mathrm{As}$ (III) ions from aqueous solutions by modification of graphene oxide with 3aminopyrazole: central composite design optimization, New J. Chem., 2017, 41(17), 8905-8919.

53 J. H. Kim, X. Ma, A. Zhou and C. Song, Ultra-deep desulfurization and denitrogenation of diesel fuel by selective adsorption over three different adsorbents: a study on adsorptive selectivity and mechanism, Catal. Today, 2006, 111(1-2), 74-83.

54 S. Mandizadeh, M. Sadri and M. Salavati-Niasari, Sol-gel auto combustion synthesis of $\mathrm{BaFe}_{18} \mathrm{O}_{27}$ nanostructures for adsorptive desulfurization of liquid fuels, Int. J. Hydrogen Energy, 2017, 42(17), 12320-12326.

55 L. Wu, G. Miao, X. Dai, L. Dong, Z. Li and J. Xiao, Ultra-deep desulfurization of real diesel using two-layer silica gels under mild conditions, Energy Fuels, 2019, 33(8), 7287-7296.

56 F. Ansari, A. Sobhani and M. Salavati-Niasari, Simple sol-gel synthesis and characterization of new $\mathrm{CoTiO}_{3} / \mathrm{CoFe}_{2} \mathrm{O}_{4}$ 
nanocomposite by using liquid glucose, maltose and starch as fuel, capping and reducing agents, J. Colloid Interface Sci., 2018, 514, 723-732.

57 S. Zinatloo-Ajabshir, M. Salavati-Niasari and Z. ZinatlooAjabshir, $\mathrm{Nd}_{2} \mathrm{Zr}_{2} \mathrm{O}_{7}-\mathrm{Nd}_{2} \mathrm{O}_{3}$ nanocomposites: new facile synthesis, characterization and investigation of photocatalytic behaviour, Mater. Lett., 2016, 180, 27-30.

58 F. Beshkar, H. Khojasteh and M. Salavati-Niasari, Recyclable magnetic superhydrophobic straw soot sponge for highly efficient oil/water separation, J. Colloid Interface Sci., 2017, 497, 57-65.

59 M. Masjedi-Arani and M. Salavati-Niasari, Novel synthesis of $\mathrm{Zn}_{2} \mathrm{GeO}_{4}$ /graphene nanocomposite for enhanced electrochemical hydrogen storage performance, Int. J. Hydrogen Energy, 2017, 42, 17184-17191.

60 A. Salehabadi, M. Salavati-Niasari and M. Ghiyasiyan-Arani, Self-assembly of hydrogen storage materials based multiwalled carbon nanotubes (MWCNTs) and $\mathrm{Dy}_{3} \mathrm{Fe}_{5} \mathrm{O}_{12}$ (DFO) nanoparticles, J. Alloys Compd., 2018, 745, 789-797.

61 S. Ahmadian-Fard-Fini, M. Salavati-Niasari and D. Ghanbari, Hydrothermal green synthesis of magnetic $\mathrm{Fe}_{3} \mathrm{O}_{4}$-carbon dots by lemon and grape fruit extracts and as a photoluminescence sensor for detecting of $\mathrm{E}$. coli bacteria, Spectrochim. Acta, Part A, 2018, 203, 481-493. 